\title{
ГОТОВНОСТЬ ПЕДАГОГА К РАБОТЕ В УСЛОВИЯХ ИНКЛЮЗИВНОГО ОБРАЗОВАНИЯ
}

\section{TEACHER'S READINESS TO WORK IN THE CONTEXT OF INCLUSIVE EDUCATION \\ L. Gosteva}

Summary: In the theoretical part of the article, inclusive education is considered as the main type of organization of education for persons with disabilities in the Russian education system. In the practical part, a study is presented to determine the level of readiness of future teachers to implement inclusive practice.

Keywords: inclusive education, inclusive process, teacher, future teacher, competence, professional competence, educator with special educational needs.
$\mathrm{B}$ настоящее время современный преподаватель должен владеть знаниями в области диагностической, реабилитационной, консультативной и корректирующей работы [3]. К педагогу выставляются высокие требования в отношении его профессиональной компетенции, что обусловлено возникновением и развитием большого разнообразия отклоняющихся форм в развитии детей, а также функционированием различных типов образовательных организаций. В свою очередь для обеспечения эффективной коррекционной образовательной помощи всем участникам инклюзивного образовательного пространства, педагогам необходимо владеть знаниями в области психофизического развития ребенка в процессе возрастного онтогенеза, учитывать общие и специфические особенности в реализации коррекционно-педагогической помощи.

Методологическую основу подготовки будущих педагогов в области инклюзивного образования представляет компетентностный подход. Компететный инклюзивный педагог - это педагог, способный качественно и содержательно решать задачи, стоящие в профессиональном плане. По результатам подготовки должен сформироваться комплекс компетенций педагога, который отразиться в способности и готовности действовать в новых и специфических условиях [2].

На современном этапе важнейшее значение имеет личность обучающегося с особыми образовательными потребностями, а именно его способность принимать самостоятельное решение и исполнять свои решения. Для реализации обозначенной тенденции система профессионального образования или дополнительной
Гостева Лилит Завеновна

Амурский государственный университет, г. Благовещенск ozzamur@mail.ru

Аннотация: В теоретической части статьи рассматривается инклюзивное образование как основной вид организации обучения лиц с ограниченными возможностями здоровья в российской системе образования. В практической части представлено исследование на определение уровня готовности будущих педагогов к реализации инклюзивной практики.

Ключевые слова: инклюзивное образование, инклюзивный процесс, педагог, будущий педагог, компетенция, профессиональная компетенция, обучающий с особыми образовательными потребностями.

профессиональной переподготовки должна быть ориентирована не только на то, чтобы повысить осведомленность педагогов в области инклюзии, но развить у них способность самостоятельного решать новые практические задачи в сложившейся инклюзивной практике.

Исследователи традиционно определяют три разновидности компетенций педагога [3]:

1. первая разновидность - это академическая компетенция (владение теоретико-методологическим аппаратом, понимание существующих в ней системных отношений и способность использовать теоретические знания на практике при решении поставленных задач).

2. вторая разновидность - профессиональная компетенция (готовность и способность действовать соответствующим образом в рамках требований педагогической практики).

3. третья разновидность - социально-личностная компетенция (комплекс навыков, имеющих отношение к особенностям личности, его способности выстраивать коммуникацию на микро, мезо и макроуровне).

Под готовностью педагога работать в условиях инклюзивной практики можно подразумевать склонность и способность к осуществлению профессиональной преподавательской деятельности в отношении обучающихся с особыми образовательными потребностями. В основе данной готовности и лежит комплекс компетенций: академических, профессиональных и социальноличностных. 
Инклюзивное образование в настоящее время представляет собой основной вид организации обучения детей инвалидов и лиц с ограниченными возможностями здоровья в большинстве систем образования мира, и российская система образования не является исключением. Под инклюзивным образованием понимается особая система образования и воспитания, в результате которой происходит полное включение обучающихся в образовательный процесс с учетом удовлетворения всех образовательных потребностей и создания соответствующих условий по каждой нозологии [1].

В нашей стране конвергенция таких видов образования как основанное и специальное осуществляется с учетом максимального интегрирования в образовательный процесс обучающихся с особенностями развития. В свою очередь под интегрированным образованием в российской практике понимается инклюзивное образование для инвалидов и лиц с ограниченными возможностями здоровья.

Надо отметить, что в результате внедрения инклюзивного образования, как специфической социокультурной технологии, появилась армия как сторонников, так и противников данного процесса. Включенное образование целью которого является адаптация образовательной и социальной среды к возможностям и потребностям конкретного обучающегося, сталкивается с теми же препятствиями, что и инклюзивное образование в целом. В перечне основных препятствий в процессе реализации инклюзивного образования, можно выделить такие как слабое научно-методическое обеспечение и материально-техническое оснащение образовательного процесса. Немаловажным моментом, препятствующим внедрению инклюзивного образования, является междисциплинарность команды специалистов, которая обладает различной спецификой культуры взаимодействия, а также система ценностей.

Для того чтобы определить уровень осознанности и готовности будущих педагогов к реализации инклюзивной практики было проведено эмпирическое исследование. Выборку составили студенты направления подготовки психолого-педагогическое образование факультета социальных наук Амурского государственного университета в количестве 15 человек.

В основе исследования лежал анкетный опрос, который предусматривал возможность открытых ответов. Интерпретация полученных данных позволила нам сформировать представление о понимании будущих педагогов особенностей реализации инклюзивного образования.

В блоке вопросов анкеты были предусмотрены вопросы, раскрывающие сущность понимания термина инклюзивное образование. Так при анализе данного вопроса было выявлено, что большинство респондентов под инклюзивным образованием понимают современное направление российской системы образования (42 \%). Вторым и третьим по распространенности ответом было понимание под инклюзивным образованием инновационной педагогической технологии (33\%) и принцип организации современного образования (25\%). Некоторые студенты проявили творческий подход и предложили свой вариант ответа.

Далее респондентам предлагалось выявить основные факторы, которые определяют качество организации и реализации инклюзивного образования. Наибольшее количество студентов (58 \%) на ведущее место определили такой фактор, как адаптация образовательных программ и учебных планов в соответствии с особыми образовательными потребностями обучающихся. Практически поровну распределились голоса респондентов в отношении междисциплинарного подхода специалистов в процессе организации обучения (31 \%) и возможности создания адаптивного образовательного процесса (30\%).

Следующий вопрос был ориентирован на выявление понимания какими личностными качествами и навыками должен обладать инклюзивный педагог. Здесь респонденты дали значительно рассеянные ответы. Большинство отметили, что обязательным компонентом является наличие специального образования, а также непрерывное повышение квалификации и самообразование (42\%). Среди социально-личностных качеств выделили такие как эмпатичность - 18 \%; толерантность - $16 \%$; способность к отзывчивости и оказанию помощи - $15 \%$; умение адаптироваться к изменяющимся условиям - $13 \%$; способность противостоять стрессам - $11 \%$. Также выделяли такие качества как развитость коммуникативных навыков (9\%) и способность командной работы (6 \%).

Респондентам предлагалось определить категории обучающихся, подлежащих охвату инклюзивным образование. В данном случае практически единодушно студенты отметили, что помимо грубых интеллектуальных и ментальных нарушений, все обучающиеся должны быть охвачены инклюзивным образованием.

На вопрос анкеты необходимо ли параллельно с инклюзивным образованием продолжать специальное в 100 \% случаев был дан положительный ответ.

В заключении по анализам полученных ответов можно отметить, что у будущих педагогов сформировано адекватное представление об инклюзивном образовании и соответствует современными научными представлениям. У студентов отмечается понимание сущности 
и содержания инклюзивного процесса, особенностей построения образовательного пространства с учетом специфики потребностей обучающихся. Однако отмечается определенная рассеянность и обтекаемость ответов, что говорит о недостаточной фиксированности и комплексности знаний в отношении инклюзивного образования как современного тренда в системе обра- зования. Таким образом, исходя из полученных данных можно утверждать, что необходимо расширить объем часов дисциплины в учебном плане студентов, обучающихся по направлению подготовки «Психолого-педагогическое образование», что позволит повысить компетентность будущих педагогов в вопросах инклюзивного образования.

\section{ЛИТЕРАТУРА}

1. Инклюзивное образование в России [Электронный ресурс]. - М. : ЮНИСЕФ, 2011. - 88 с. - Режим доступа http://issuu.com/rooiperspektiva/docs/ inclusiverussia. - Дата доступа : 12.11.2021.

2. Никитина М.И. Формирование профессиональной компетенции педагогов инклюзивного образования / М.И. Никитина, М.Ф. Баулина // Вестник ЛГУ им. А.С. Пушкина. 2016. №4-2. URL: https://cyberleninka.ru/article/n/formirovanie-professionalnoy-kompetentsii-pedagogov inklyuzivnogo-obrazovaniya - Дата доступа : 17.11.2021.

3. Логинова Е.Т. Разноуровневая подготовка педагогов в условиях инклюзивного образования / Е.Т. Логинова // Специальное образование: материалы XI Междунар. науч. конф.; под общ. ред. В. Н. Скворцова. - СПб., 2015. - С. 29-33.

(с) Гостева Лилит Завеновн (ozzamur@mail.ru).

Журнал «Современная наука: актуальные проблемы теории и практики»

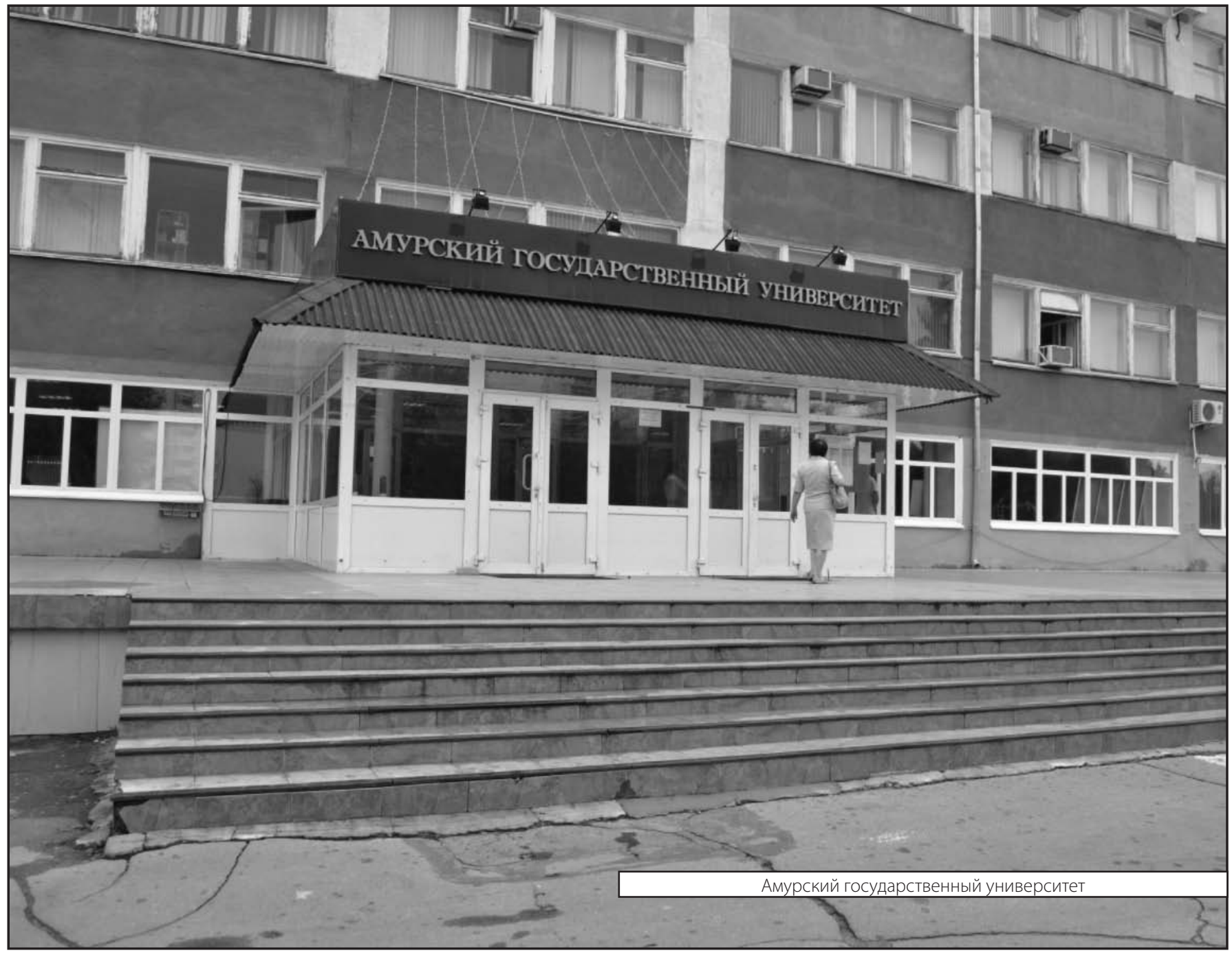

